\title{
Salicylic acid metabolites and derivatives inhibit CDK activity: Novel insights into aspirin's chemopreventive effects against colorectal cancer
}

\author{
RAKESH DACHINENI $^{1}$, D. RAMESH KUMAR ${ }^{1,3}$, EDUARDO CALLEGARI $^{2}$, SIDDHARTH S. KESHARWANI $^{1}$, \\ RANJINI SANKARANARAYANAN ${ }^{1}$, TERESA SEEFELDT ${ }^{1}$, HEMACHAND TUMMALA ${ }^{1}$ and G. JAYARAMA BHAT ${ }^{1}$ \\ ${ }^{1}$ Department of Pharmaceutical Sciences and Translational Cancer Research Center, \\ South Dakota State University College of Pharmacy and Allied Health Professions, Brookings, SD 57007; \\ ${ }^{2}$ SD-BRIN Proteomic Facility, University of South Dakota School of Medicine, Vermillion, SD 57069, USA
}

Received July 26, 2017; Accepted September 20, 2017

DOI: $10.3892 /$ ijo.2017.4167

\begin{abstract}
Aspirin's potential as a drug continues to be evaluated for the prevention of colorectal cancer (CRC). Although multiple targets for aspirin and its metabolite, salicylic acid, have been identified, no unifying mechanism has been proposed to clearly explain its chemopreventive effects. Our goal here was to investigate the ability of salicylic acid metabolites, known to be generated through cytochrome P450 (CYP450) enzymes, and its derivatives as cyclin dependent kinase (CDK) inhibitors to gain new insights into aspirin's chemopreventive actions. Using in vitro kinase assays, for the first time, we demonstrate that salicylic acid metabolites, 2,3-dihydroxybenzoic acid (2,3-DHBA) and 2,5-dihydroxybenzoic acid (2,5-DHBA), as well as derivatives 2,4-dihydroxybenzoic acid (2,4-DHBA), 2,6-dihydroxybenzoic acid (2,6-DHBA), inhibited CDK1 enzyme activity. 2,3-DHBA and 2,6-DHBA did not inhibit CDK2 and 4; however, both inhibited CDK-6 activity. Interestingly, another derivative, 2,4,6-trihydroxybenzoic acid (2,4,6-THBA) was highly effective in inhibiting CDK1, 2, 4 and 6 activity. Molecular docking studies showed that these compounds potentially interact with CDK1. Immunoblotting experiments showed that aspirin acetylated CDK1, and preincubation with salicylic acid and its derivatives prevented aspirin-mediated CDK1 acetylation, which supported the data obtained from molecular docking studies. We suggest that
\end{abstract}

Correspondence to: Dr G. Jayarama Bhat, Department of Pharmaceutical Sciences, South Dakota State University College of Pharmacy and Allied Health Professions, Avera Health and Sciences Center, 1055 Campanile Avenue, Brookings, SD 57007, USA

E-mail: jayarama.gunaje@sdstate.edu

Present address: ${ }^{3}$ University of Kentucky, Lexington, KY40546, USA

Key words: chemoprevention, colorectal cancer, cyclins, CDKs and CDK inhibitors, aspirin, salicylic acid, salicylic acid binding protein, gallic acid, gentisic acid, polyphenols intracellularly generated salicylic acid metabolites through CYP450 enzymes within the colonic epithelial cells, or the salicylic acid metabolites generated by gut microflora may significantly contribute to the preferential chemopreventive effect of aspirin against CRC through inhibition of CDKs. This novel hypothesis and mechanism of action in aspirin's chemopreventive effects opens a new area for future research. In addition, structural modification to salicylic acid derivatives may prove useful in the development of novel CDK inhibitors in cancer prevention and treatment.

\section{Introduction}

Increasing evidence from epidemiological studies and randomized clinical trials have suggested that aspirin decreases the incidence of colorectal cancers (CRC) (1-4). Most of aspirin's chemopreventive effects came to light during the course of its use as a cardio-protective and/or analgesic agent. It was observed that aspirin at doses ranging from 75 to $325 \mathrm{mg}$, when taken regularly over 5-10 years decreases the incidence and mortality associated with CRC $(1,4)$. The low-dose $75 \mathrm{mg}$ aspirin was just as effective as the high-dose in preventing CRC. Studies also revealed that aspirin is more effective against CRC as compared to the cancers of other tissues such as breast, prostate, liver, lung, and skin (5-7).

Aspirin is mainly absorbed in the acidic environment of the stomach and upper intestine. The oral bioavailability of aspirin is $40-50 \%$ (8); it undergoes hydrolysis in the intestine, liver, and plasma by esterases (9). In contrast to the short halflife of intact aspirin (20 min), salicylic acid, depending upon the dose, has a half-life varying between 4 to $6 \mathrm{~h}$, and remains much longer in the plasma. In the liver, salicylic acid undergoes further metabolism through glucuronide formation to produce ester and ether glucuronides (1-42\%), or conjugation with glycine to produce salicyluric acid (20-65\%). In addition, the cytochrome P450 (CYP450) enzymes in the liver metabolize salicylic acid to 2,5-dihydroxybenzoic acid (2,5-DHBA, genitisic acid) and 2,3-dihydrozybenzoic acid (2,3-DHBA), which accounts for less than $1 \%$ of the salicylic acid metabolites. The 2,5-DHBA can undergo conjugation with glycine to 
form gentisuric acid. These metabolites are eliminated from the body either through the kidneys or bile (10-12).

Our laboratory has been investigating the hypothesis that aspirin and salicylic acid may target cell cycle regulatory proteins to exert their chemopreventive effects. Cyclin dependent kinases (CDKs) are key regulators of the cell cycle, and are activated by binding with temporally expressed cyclins during various stages of the cell cycle. The important CDKs in mammalian cell cycle regulation are: CDK1, CDK2, CDK4 and CDK6. CDK4 and CDK6, through binding to cyclin D, facilitate the progression through $\mathrm{G} 1$, whereas, CDK2 via binding to cyclin $\mathrm{E}$ helps to transition from $\mathrm{G} 1$ to $\mathrm{S}$ phase. CDK1 and CDK2 get activated via binding to cyclins $A$ and $B$, which facilitate the progression through G2 and M phases. In many cancers, CDKs are deregulated and cyclins are over expressed (13). Due to their important regulatory role in cell cycle progression, CDKs have been attractive targets in cancer treatment (14-16), in this regard only two CDK inhibitors (palbociclib and ribociclib) specific to CDK4 and 6 have been approved for cancer treatment, which are classified as ATP-competitive inhibitors $(17,18)$.

In our previous study, we demonstrated that exposure of colon cancer cells, to aspirin and salicylic acid caused downregulation of cyclin A2, B1 and D3, and CDKs 1, 2, 4 and 6 (19). In that study, we also demonstrated that salicylic acid potentially binds to CDK2 via interactions with Asp145, and Lys33, both of which are found in the active site of the enzyme. Despite these potential interactions, salicylic acid failed to inhibit the CDK2 enzyme activity in an in vitro kinase assays. In this study, we considered the possibility that the two salicylic acid metabolites 2,3-DHBA and 2,5-DHBA, which are known to be produced through CYP450 catalyzed reactions may inhibit CDK enzyme activity. The goal of the present study was to determine the effect of salicylic acid metabolites (2,3-DHBA and 2,5-DHBA) and also derivatives (2,4-DHBA, 2,6-DHBA and 2,4,6-trihydroxybenzoic acid) on CDK activity in vitro, and determine the potential sites of interactions with CDK-1.

Herein, we report that salicylic acid metabolites 2,3-DHBA and 2,5-DHBA, as well as the salicylic acid derivatives 2,4-DHBA and 2,6-DHBA, inhibited CDK1 enzyme activity. The trihydroxy derivative of salicylic acid, 2,4,6-THBA, was also highly effective. While 2,3-DHBA and 2,5-DHBA are produced from the oxidation of salicylic acid through CYP450 metabolism, they are also reported to be naturally present in several fruits and medicinal herbs. This is the first report demonstrating the ability of salicylic acid metabolites, and naturally occurring salicylic acid derivatives to inhibit CDK activity, suggesting their potential role in chemoprevention.

\section{Materials and methods}

Cell lines. HCT-116 human colorectal carcinoma cell line was purchased from American Type Culture Collection (ATCC). The cells were cultured in McCoy's 5A medium containing $10 \%$ FBS for $24 \mathrm{~h}$ before treatment with specified compounds for indicated times (20). Authentication of cell lines was done by ATCC through their DNA-STR profile.

Reagents. Aspirin, salicylic acid, 2,4,6-THBA, 3,4,5-THBA and trypsin-EDTA solution were purchased from Sigma (St. Louis,
MO, USA); Immobilon membranes, H1 Histones from EMD Millipore (Billerica, MA, USA); ${ }^{32} \mathrm{P} \gamma$-ATP were from MP Biochemical; Super Signal $^{\text {TM }}$ West Pico Chemiluminescent Substrate, 2,3-DHBA, 2,4-DHBA, 2,5-DHBA, 2,6-DHBA, 3,4-DHBA, 3,5-DHBA, 2,4,6-THBA and protease inhibitor tablets and all other chemicals were obtained from Thermo Fisher Scientific, Inc. (Waltham, MA, USA).

Recombinant proteins and antibodies. Anti-CDK1 and anti- $\beta$ actin antibodies were purchased from Cell Signaling Technology (Danvers, MA, USA); Anti-acetyl lysine conjugated agarose beads from Immune Chem (Burnaby, BC, Canada); goat anti-rabbit and goat anti-mouse antibodies were obtained from Bio-Rad (Hercules, CA, USA). CDK1/ cyclin B1 active enzyme from New England Biolabs (NEB) (Ipswich, MA, USA), CDK1/cyclin B1, CDK2/cyclin A2, CDK4/cyclin D1, CDK6/cyclin D1, Retinoblastoma (C-term) and kinase buffer were purchased from SignalChem (Richmond, BC, Canada).

Cell lysate preparation and western blotting. After treatment with aspirin at the indicated concentrations, cells were washed with phosphate buffered saline and scraped into lysis buffer and protein extracts were prepared as previously described (21). Samples containing $50 \mu \mathrm{g}$ of protein were separated by $8 \%$ polyacrylamide gel electrophoresis (PAGE) and immunoblotted with respective antibodies. For immunoprecipitations, $500 \mu \mathrm{g}$ of the protein was immunoprecipitated with anti-acetyl lysine conjugated agarose beads overnight, immunocomplexes were collected, and immunoblotted with anti-CDK1 antibody. Intensities of the bands were quantified using NIH ImageJ software.

In vitro $C D K$ assay. In vitro $\mathrm{CDK}$ assays were performed as described by the protocols from NEB and SignalChem. Briefly, purified kinase was aliquoted into the reaction buffer provided by the respective kits and incubated with indicated compounds at various concentrations for $10 \mathrm{~min}$ at room temperature. Kinase reaction were performed by incubating the enzyme with a kinase buffer containing $15 \mu \mathrm{M}$ ATP, $2 \mu \mathrm{Ci}$ of $\left[\gamma^{-32} \mathrm{P}\right] \mathrm{ATP}, 5 \mu \mathrm{g}$ of $\mathrm{H} 1 \mathrm{Histone}$ or retinoblastoma, at $30^{\circ} \mathrm{C}$ for $20 \mathrm{~min}$. The final volume of the reaction was $50 \mu \mathrm{l}$, the reactions were stopped by adding EDTA to a final concentration of $20 \mathrm{mM}$ and $4 \mathrm{X}$ loading buffer. The samples were boiled for $10 \mathrm{~min}$, loaded on to a $10 \%$ SDS-PAGE. The gel was stained using Coomassie Brilliant blue (R), dried and exposed to X-ray film. Intensities of the bands were quantified using NIH ImageJ software.

MTT Assay. Cytotoxicity was determined by MTT [3-(4,5-dimethylthiazol-2-yl)-2,5-diphenyltetrazolium bromide] assay. Briefly, HCT-116 cells were seeded in 24-well plates overnight at a density of 20,000 cells/well and treated with various compounds for $72 \mathrm{~h}$. MTT assays were carried out as previously described (22).

Molecular docking studies. The crystallographic three dimensional structures of selected target proteins of CDK1 (4y72 A chain) and cyclin b1 (PDB ID: 2b9r) were retrieved from the Protein Data Bank (PDB) http://www.pdb.org. The 
A
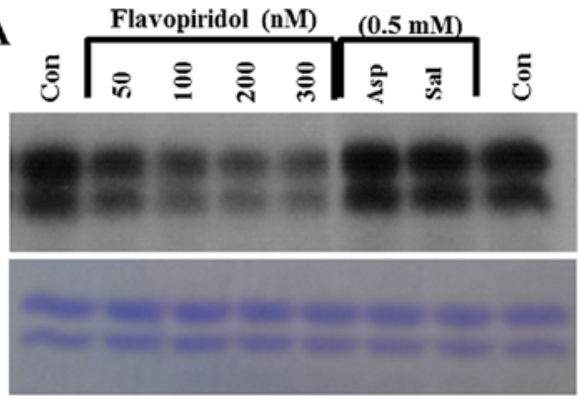

Coomassie stained H1 histones

B

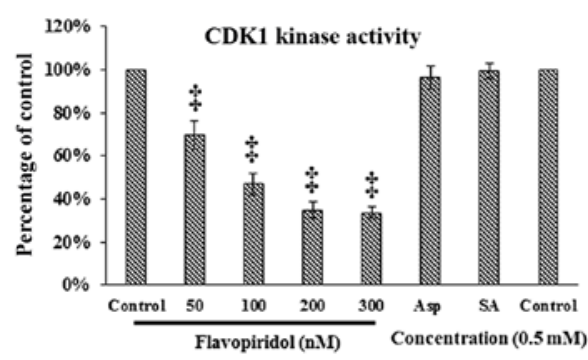

E

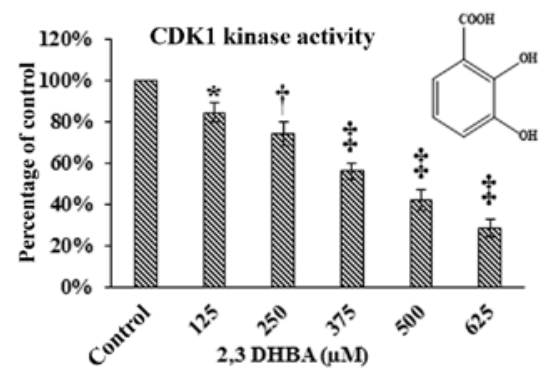

F

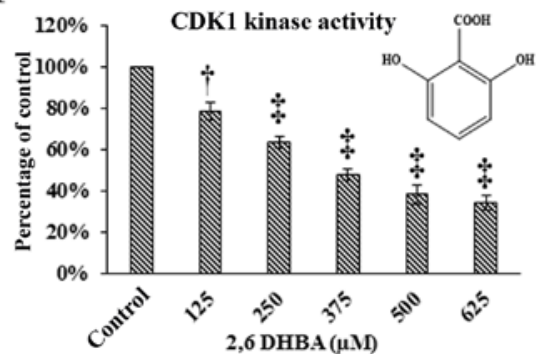

C
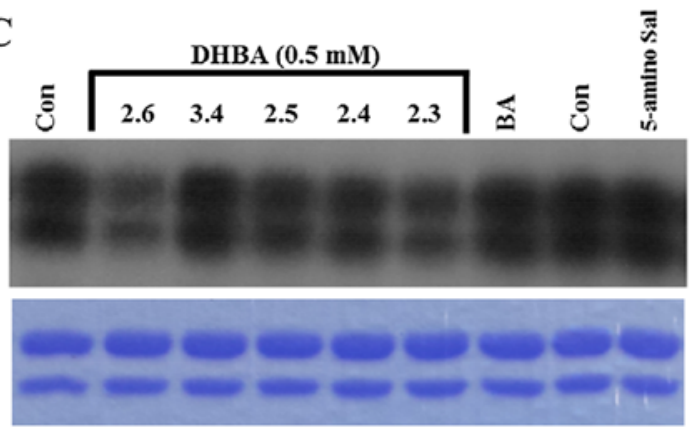

D

Coomassie stained $\mathrm{H} 1$ histones

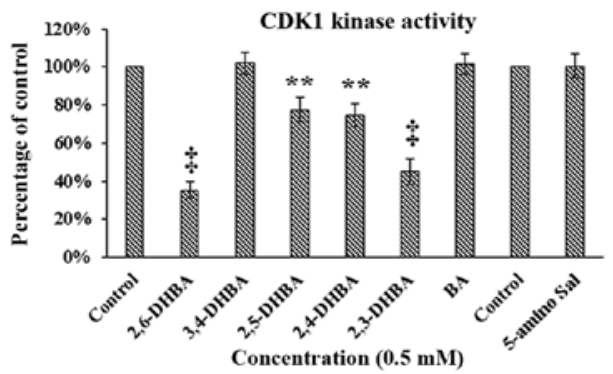

2,4,6-THBA $(\mu \mathrm{M})$

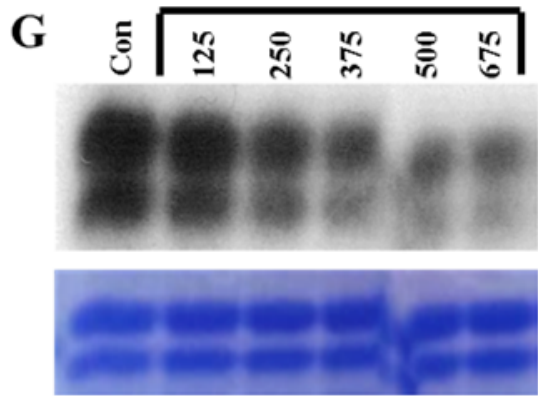

Coomassie stained H1 histones

H

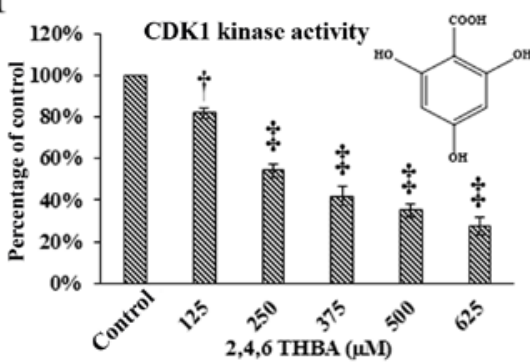

Figure 1. In vitro kinase assays showing the effect of aspirin, salicylic acid metabolites and derivatives on CDK1 enzyme activity. (A) Effect of aspirin (Asp), salicylic acid (Sal) and flavopiridol on CDK1 enzyme activity. (B) Quantification of the blot in (A). (C) Effect of salicylic acid metabolites 2,3-DHBA, 2,5-DHBA and derivatives 2,4-DHBA, 2,6-DHBA, 3,4-DHBA, 5-amino salicylic acid (5-amino Sal), and benzoic acid (BA) on CDK1 enzyme activity. The lower panels below (A and C) shows coomassie stained H1 histones. (D) quantification of the blot in (C). (E and F) The dose-dependent effect of 2,3-DHBA and 2,6-DHBA on CDK1 enzyme activity. (G) Dose-dependent effect of 2,4.6-THBA on CDK1. The lower panel of (G), shows coomassie stained pattern of histone $(\mathrm{H}) .(\mathrm{H})$ Quantification of the blot in $(\mathrm{G})$. The intensities of bands in various blots were quantified and expressed as percentage of control. * $\mathrm{P}<0.05$, ${ }^{* *} \mathrm{P}<0.01,{ }^{\dagger} \mathrm{P}<0.001,{ }^{\ddagger} \mathrm{P}<0.001$.

human CDK1, Cyclin b1 and CDK1_cyclin b1 complex (PDB ID: $2 \mathrm{~b} 9 \mathrm{r}$ and $4 \mathrm{y} 72$ ) were selected for energy minimization using Gromacs 3.3.1 package with the GROMOS96 force field (23). These molecules were used as the receptor for virtual small molecule docking with ligand aspirin, salicylic acid, 2,3-DHBA, 2,5-DHBA, 2,6-DHAB and 2,4,6 THBA using AutoDockVina. The molecular results were visualized by PYMOL molecular graphics system version 1.3.

Statistical analysis. All experiments were repeated 3-6 times independently of each other. One-way ANOVA followed by Tukey's post-hoc multiple comparison tests were adopted to 

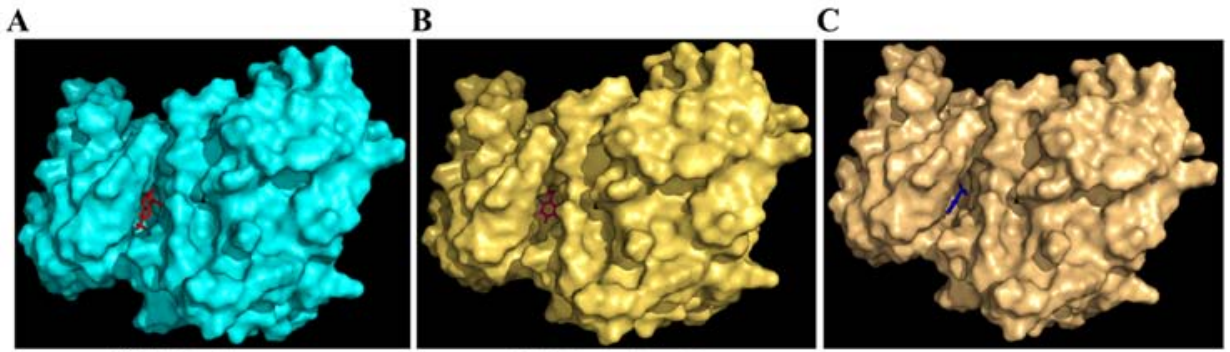

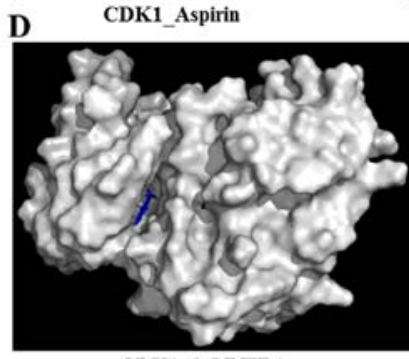

CDK1_2,5 DHBA

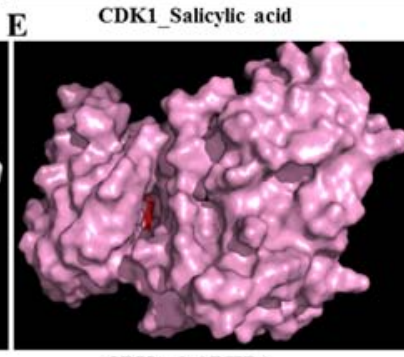

CDK1_2,6 DHBA

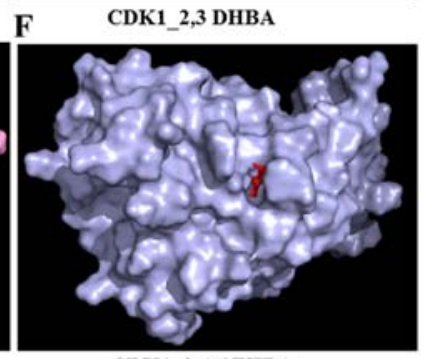

CDK1_2,4,6 THBA

Figure 2. Molecular docking studies (space-filling model) showing the potential binding pockets in CDK1 for aspirin (A), salicylic acid (B), 2,3-DHBA (C), 2,5-DHBA (D), 2,6-DHBA (E) and 2,4,6-THBA (F).

compare group differences to control, and significance was defined at $\mathrm{P}<0.05$.

\section{Results}

Effect of aspirin, salicylic acid and salicylic acid metabolites and derivatives on CDK1 kinase activity in vitro. In a previous study, we demonstrated that aspirin potentially binds to CDK2 through Lys33 and salicylic acid via Asp145 and Lys33. Despite the strong evidence of interactions of these drugs with CDK2, both failed to inhibit CDK2 enzyme activity in in vitro kinase assays (19). In the current study, we initially extended these observations to determine the effect of aspirin and salicylic acid on CDK1 enzyme activity in vitro. This was tested using commercially obtained CDK1/cyclin B1 assay kits, and by providing $\left[\gamma_{-}{ }^{32} \mathrm{P}\right] \mathrm{ATP}$ and $\mathrm{H} 1$ histones as substrates. As a positive control, we used flavopiridol, a known inhibitor of CDK1 (24). Fig. 1A demonstrates that neither aspirin nor salicylic acid inhibited CDK1 activity as measured by the ability to phosphorylate H1 histones; however, flavopiridol dose-dependently inhibited CDK1 activity (upper panel). These samples contained similar levels of $\mathrm{H} 1$ histones (lower panel, Fig. 1A). Quantification of the bands in Fig. 1A (upper panel) are shown in Fig. 1B. These results show that aspirin and salicylic acid do not inhibit CDK1, consistent with the results previously obtained with CDK2 (19).

We next determined the ability of salicylic acid metabolites (2,3-DHBA and 2,5-DHBA) as we all as salicylic acid derivatives (2,4-DHBA, 2,6-DHBA and 3,4-DHBA and 5-aminosalicylic acid) and benzoic acid to inhibit CDK-1 enzyme activity. We observed that, of the seven different compounds tested, all DHBA compounds with a common -OH group at the 2nd carbon inhibited CDK1 enzyme activity to varying degrees (Fig. 1C, upper panel). It is interesting to note that the salicylic acid metabolites, 2,3-DHBA and 2,5-DHBA, both showed inhibitory effects on CDK1 activity. Quantification of the intensities of the bands showed that, four compounds showed varied levels of inhibition (2,6-DHBA,
65\%; 2,5-DHBA, 22\%; 2,4-DHBA, 25\% and 2,3-DHBA, 55\%) (Fig. 1D). Three compounds, 3,4-DHBA, 5-aminosalicylic acid and benzoic acid did not show any inhibition. In addition, 3,5-DHBA failed to inhibit the CDK1 enzyme activity (data not shown).

Dose-dependent inhibition of CDK1 enzyme activity by 2,3-DHBA, 2,6-DHBA and 2,4,6-THBA. In experiments described in Fig. 1C, the salicylic acid metabolite 2,3-DHBA, and the salicylic acid derivative 2,6-DHBA, showed greater inhibition on CDK1 activity as compared to other compounds tested. Therefore, we focused initially on these two compounds to study their dose-dependent effects on CDK1 activity. Fig. 1E and $\mathrm{F}$ show that both 2,3-DHBA and 2,6-DHBA dosedependently inhibit CDK1 activity with an $\mathrm{IC}_{50}$ of $386 \mu \mathrm{M}$ and $365 \mu \mathrm{M}$, respectively. The ability of 2,3-DHBA and 2,6-DHBA to inhibit CDK1 enzyme activity suggested that the hydroxyl group at the 2 nd and 6th carbon in these compounds may be important, and that a compound having these two-OH groups may more potently inhibit CDK 1 activity. Therefore, in in vitro kinase assays, we determined the effect of 2,4,6-THBA on CDK1 activity at various concentrations. Fig. $1 \mathrm{G}$ (upper panel) demonstrates that 2,4,6-THBA inhibited CDK1 activity with an $\mathrm{IC}_{50}$ of $226 \mu \mathrm{M}$. Quantification of the bands are shown in Fig. 1H. Of note, 3,4,5-THBA (gallic acid) did not show any inhibitory effect (data not shown). This again suggests that the -OH group at the 2nd and 6th carbon may contribute to greater inhibition of CDK1 enzyme activity.

Molecular docking studies show potential interactions of aspirin, salicylic acid, salicylic acid metabolites and derivatives with CDK1 and cyclin B1. We used AutoDockVina to understand the interactions between aspirin, salicylic acid, 2,3-DHBA, 2,5-DHBA 2,6-DHBA and 2,4,6-THBA with CDK1 alone, cyclin B1 alone, and the CDK1/cyclinB1 complex. The binding free energy and hydrogen bond lengths were also determined. The results of the docking studies are shown in Table I, Fig. 2A-F (space-filling model) and Figs. 3-5. 
Table I. Molecular docking studies of CDK1/Cyclin B1 with metabolites/derivatives of aspirin.

\begin{tabular}{|c|c|c|c|c|c|c|c|c|}
\hline S. no. & Ligand & Receptor & PDB ID & $\begin{array}{l}\text { Interacting } \\
\text { amino acids }\end{array}$ & $\begin{array}{l}\text { No. of } \\
\text { H-bonds }\end{array}$ & $\begin{array}{c}\text { Measurement } \\
\left(\mathrm{A}^{0}\right)\end{array}$ & $\begin{array}{l}\text { Energy value } \\
(\mathrm{kcal} / \mathrm{mol})\end{array}$ & Interactions \\
\hline 1 & Aspirin & CDK1 & $\begin{array}{l}4 y 72 \\
\text { (A Chain) }\end{array}$ & $\begin{array}{l}\text { Asn } 133, \text { Gln132 } \\
\text { and Tyr15 }\end{array}$ & 3 & $\begin{array}{l}2.7,2.1 \\
\text { and } 2.6\end{array}$ & -7.4 & $\begin{array}{l}\text {-COOH - Asn133, } \\
\text { Gln132 and Tyr15 }\end{array}$ \\
\hline 2 & $\begin{array}{l}\text { Salicylic } \\
\text { acid }\end{array}$ & CDK1 & $\begin{array}{l}4 y 72 \\
\text { (A chain) }\end{array}$ & $\begin{array}{l}\text { Asp } 146 \text { and } \\
\text { Lys } 33\end{array}$ & 2 & 1.8 and 2.5 & -8.6 & $\begin{array}{l}\text {-OH - Lys33; } \\
\text {-COOH - Asp146 }\end{array}$ \\
\hline 3 & 2,3-DHBA & CDK1 & $\begin{array}{l}4 y 72 \\
\text { (A Chain) }\end{array}$ & Asp146 & 1 & 2.0 & -6.8 & -COOH - Asp146 \\
\hline 4 & 2,5-DHBA & CDK1 & $\begin{array}{l}4 y 72 \\
\text { (A Chain) }\end{array}$ & Asp146 & 1 & 2.1 & -6.8 & -COOH - Asp146 \\
\hline 5 & 2,6-DHBA & CDK1 & $\begin{array}{l}4 y 72 \\
\text { (A Chain) }\end{array}$ & Asp146 & 1 & 2.0 & -7.1 & 6th -OH - Asp146 \\
\hline 6 & 2,4,6-ТHBA & CDK1 & $\begin{array}{l}4 y 72 \\
\text { (A Chain) }\end{array}$ & $\begin{array}{l}\text { Arg123, } \\
\text { Arg151 and } \\
\text { Gly154 }\end{array}$ & 3 & $\begin{array}{l}2.5,2.0 \\
\text { and } 2.4\end{array}$ & -5.8 & $\begin{array}{l}\text { 2nd -OH - Arg151 } \\
\text { and Gly } 154 ; \\
\text {-COOH -Arg } 123\end{array}$ \\
\hline 7 & Aspirin & Cyclin B1 & $2 b 9 r$ & Arg135 & 2 & 1.9 and 2.5 & -6.8 & -COOH Arg135 \\
\hline 8 & $\begin{array}{l}\text { Salicylic } \\
\text { acid }\end{array}$ & Cyclin B1 & $2 b 9 r$ & $\begin{array}{l}\text { Arg135 and } \\
\text { Tyr60 }\end{array}$ & 4 & $\begin{array}{l}2.2,2.4,2.7 \\
\text { and } 2.3 \mathrm{~A}\end{array}$ & -7.4 & $\begin{array}{l}\text {-OH - Arg135; } \\
\text {-COOH - Tyr60, } \\
\text { Arg135 }\end{array}$ \\
\hline 9 & 2,3-DHBA & Cyclin B1 & $2 b 9 r$ & $\begin{array}{l}\text { Arg135, Arg38 } \\
\text { and Asp67 }\end{array}$ & 6 & $\begin{array}{l}2.1,2.2,2.2, \\
2.2,2.4 \\
\text { and } 2.3\end{array}$ & -6.8 & $\begin{array}{l}\text { 2nd -OH - Asp67; } \\
\text { 3rd - OH -COOH } \\
\text { - Arg38; Arg135 }\end{array}$ \\
\hline 10 & 2,5-DHBA & Cyclin B1 & $2 b 9 r$ & $\operatorname{Arg} 135$ & 2 & 2.0 and 2.4 & -6.7 & 2nd -OH - Arg135 \\
\hline 11 & 2,6-DHBA & Cyclin B1 & $2 b 9 r$ & Arg135 & 2 & 2.1 and 2.5 & -5.4 & 6th $-\mathrm{OH}-\mathrm{Arg} 135$ \\
\hline 12 & 2,4,6-ТHBA & Cyclin B1 & $2 b 9 r$ & $\begin{array}{l}\text { Arg135, } \\
\text { Phe175, } \\
\text { Asp67, Arg38, } \\
\text { Thr166 }\end{array}$ & 6 & $\begin{array}{l}2.2,2.4,2.2, \\
2.2,2.3 \\
\text { and } 2.1\end{array}$ & -6.8 & $\begin{array}{l}\text { 2nd -OH - Asp67; } \\
\text { 4th -OH - Arg38, } \\
\text { Thr166; 6th -OH } \\
\text { - Asp67; -COOH } \\
\text { - Arg135 }\end{array}$ \\
\hline 13 & Aspirin & $\begin{array}{l}\text { CDK1_ } \\
\text { Cyclin B1 }\end{array}$ & $\begin{array}{l}4 y 72 \\
\text { (A, B chain) }\end{array}$ & Tyr15 (CDK1) & 1 & 2.5 & -7.0 & $\begin{array}{l}\text {-COOH - Tyr15 } \\
\text { (CDK1) }\end{array}$ \\
\hline 14 & $\begin{array}{l}\text { Salicylic } \\
\text { acid }\end{array}$ & $\begin{array}{l}\text { CDK1_- } \\
\text { Cyclin B1 }\end{array}$ & $\begin{array}{l}4 y 72 \\
\text { (A, B chain) }\end{array}$ & $\begin{array}{l}\text { Asp146 and } \\
\text { Lys33 } \\
(\mathrm{CDK} 1)\end{array}$ & 3 & $\begin{array}{l}1.9,2.5 \\
\text { and } 2.6\end{array}$ & -9.6 & $\begin{array}{l}\text {-OH - Asp146; } \\
\text {-COOH - Lys33, } \\
\text { Asp146 (CDK1) }\end{array}$ \\
\hline 15 & 2,3-DHBA & $\begin{array}{l}\text { CDK1_- } \\
\text { Cyclin B1 }\end{array}$ & $\begin{array}{l}4 y 72 \\
\text { (A, B chain) }\end{array}$ & $\begin{array}{l}\text { Thr329, } \\
\text { Val336, } \\
\text { Phe338 } \\
\text { (Cyclin B1) }\end{array}$ & 2 & $\begin{array}{l}2.4,2.1 \\
\text { and } 2.4\end{array}$ & -6.1 & $\begin{array}{l}\text { 2nd and 3rd -OH } \\
\text { - Phe338; 3rd -OH } \\
\text { Val336; -COOH - } \\
\text { Thr329 (cyclin B1) }\end{array}$ \\
\hline 16 & 2,5-DHBA & $\begin{array}{l}\text { CDK1_- } \\
\text { Cyclin B1 }\end{array}$ & $\begin{array}{l}4 y 72 \\
\text { (A, B chain) }\end{array}$ & $\begin{array}{l}\operatorname{Arg} 123(3), \\
\text { Leu125, and } \\
\text { Arg151 } \\
(\text { CDK1) }\end{array}$ & 5 & $\begin{array}{l}2.2,2.2,2.4, \\
2.4 \text { and } 2.4\end{array}$ & -6.0 & $\begin{array}{l}\text { 5th -OH - Leu125 } \\
\text { and Arg151; } \\
\text {-COOH - Arg123 } \\
\text { (CDK1) }\end{array}$ \\
\hline 17 & 2,6-DHBA & $\begin{array}{l}\text { CDK1_- } \\
\text { Cyclin B1 }\end{array}$ & $\begin{array}{l}4 y 72 \\
\text { (A, B chain) }\end{array}$ & $\begin{array}{l}\text { Val336 } \\
\text { (Cyclin B1) }\end{array}$ & 1 & 2.6 & -5.6 & $\begin{array}{l}\text { 6th -OH - Val336 } \\
\text { (cyclin B1) }\end{array}$ \\
\hline 18 & 2,4,6-ТHBA & $\begin{array}{l}\text { CDK1_- } \\
\text { Cyclin B1 }\end{array}$ & $\begin{array}{l}4 y 72 \\
\text { (A, B chain) }\end{array}$ & $\begin{array}{l}\text { Tyr223, } \\
\text { Asp 230, } \\
\text { and Arg201 } \\
\text { (Cyclin B1) }\end{array}$ & 2 & $\begin{array}{l}2.3,2.5 \text { and } \\
2.5\end{array}$ & -5.4 & $\begin{array}{l}\text { 2nd -OH - Asp230; } \\
\text { 4th -OH - Tyr223; } \\
\text {-COOH - Arg201 } \\
\text { (cyclin B1) }\end{array}$ \\
\hline
\end{tabular}

Free energy binding values and hydrogen bond lengths for the interaction of aspirin, salicylic acid, 2,3-DHBA, 2,5-DHBA, 2,6-DHBA and 2,4,6-THBA with CDK1, cyclin B1 and CDK1/cyclin B1 complex. 


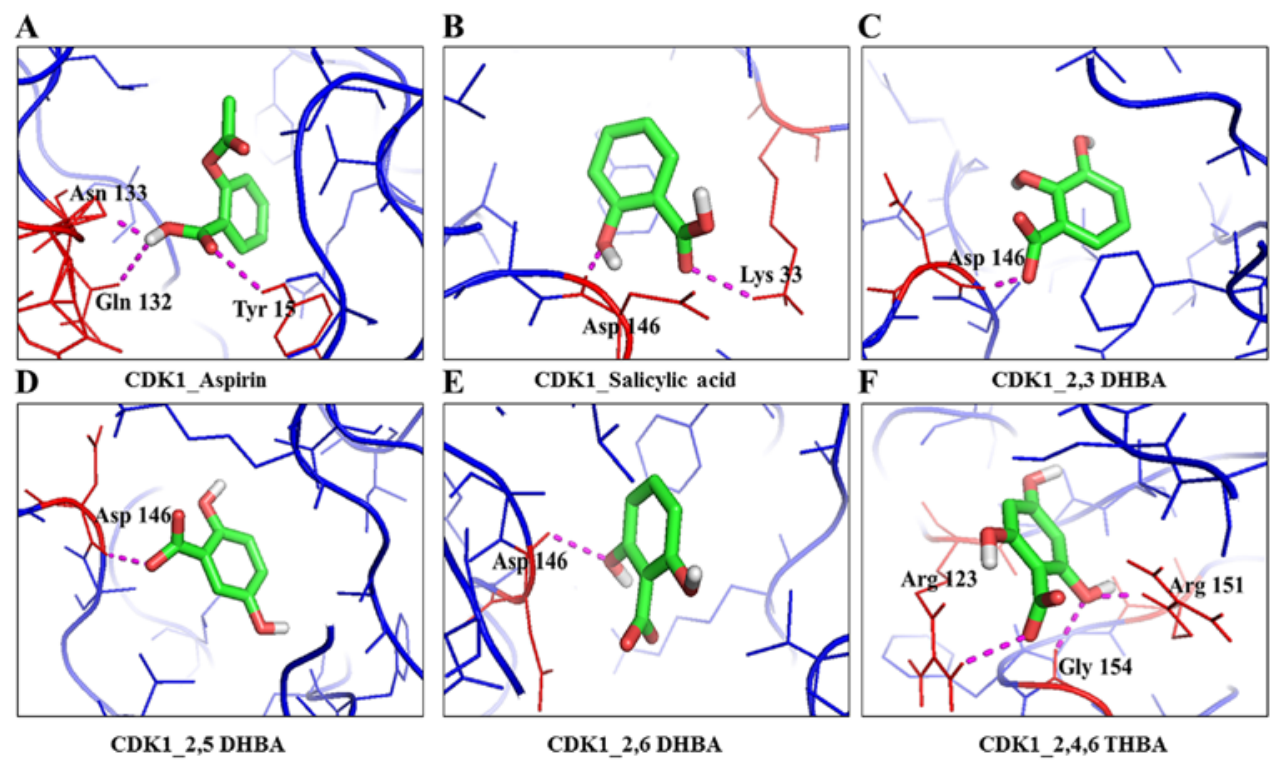

Figure 3. Molecular docking studies showing the potential interactions of aspirin (A), salicylic acid (B), 2,3-DHBA (C), 2,5-DHBA (D), 2,6-DHBA (E) and 2,4,6-THBA (F) with CDK1.
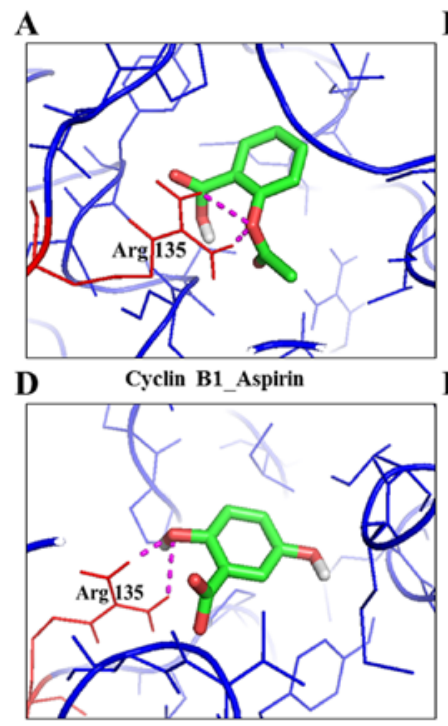

Cyclin B1 2,5 DHBA
B

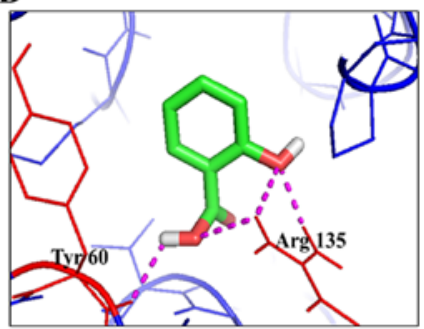

E Cyclin B1_Salicylic acid

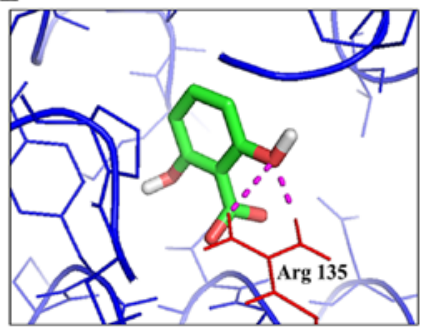

Cyclin B1 2,6 DHBA

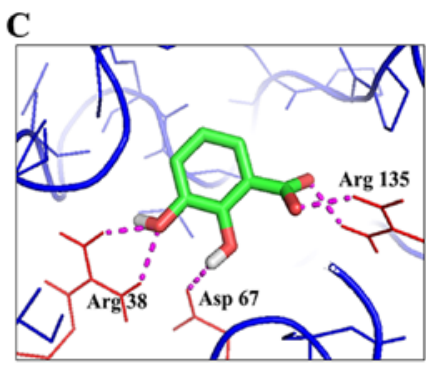

F Cyclin B1_2,3 DHBA

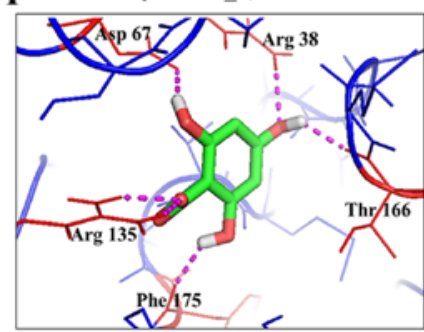

Cyclin B1 2,4,6 THBA

Figure 4. Molecular docking studies showing the potential interactions of aspirin (A), salicylic acid (B), 2,3-DHBA (C), 2,5-DHBA (D), 2,6-DHBA (E) and 2,4,6-THBA (F) with cyclin B1.

Among the potential interactions shown in Table I, salicylic acid interactions with CDK1 through Asp146 and Lys33 is significant as these two amino acids are part of the active site of the enzyme and are conserved among different CDK family members (25). Noteworthy, salicylic acid also interacts with CDK1 through Asp146 and Lys33 when it is present as part of the cyclin B1/CDK1 complex (Table I). Docking studies also revealed that aspirin can potentially interact with Tyr- 15 in the CDK1 monomer, or in the CDK1/cyclin B1 dimer. It is interesting to note that Tyr15 is conserved in various CDKs, and its phosphorylation by Wee1/Mik1 kinase family inactivates the enzyme activity (26). Despite these predicted interactions of aspirin and salicylic acid with key amino acid residues in CDK1, both failed to inhibit CDK1 enzyme activity (Fig. 1).
Table I also shows that all three DHBA compounds (2,3-DHBA, 2,5-DHBA and 2,6-DHBA) showed potential interactions with CDK1 monomer through Asp 146, whereas 2,4,6-THBA interacted via Arg123, Arg151 and Gly154. Fig. 2A-F (space-filling model) shows that 2,3-DHBA, 2,5-DHBA and 2,6-DHBA bind to the same pocket in CDK1 (same as aspirin and salicylic acid); however, 2,4,6-THBA binds at a different site. Interestingly, all four compounds (DHBAs/ THBA) inhibited CDK1 enzyme activity (Fig. 1C-H).

Aspirin acetylates recombinant $C D K 1$, and pre-incubation with salicylic acid, 2,3-DHBA, 2,6-DHBA or 2,4,6-THBA inhibits aspirin's ability to acetylate CDK1. We performed experiments to provide a second line of evidence for the 


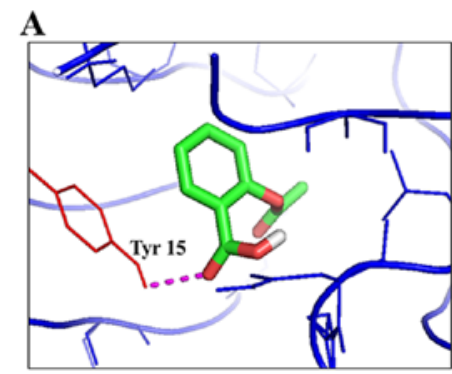

CDK1/Cyclin B1 Aspirin D
B

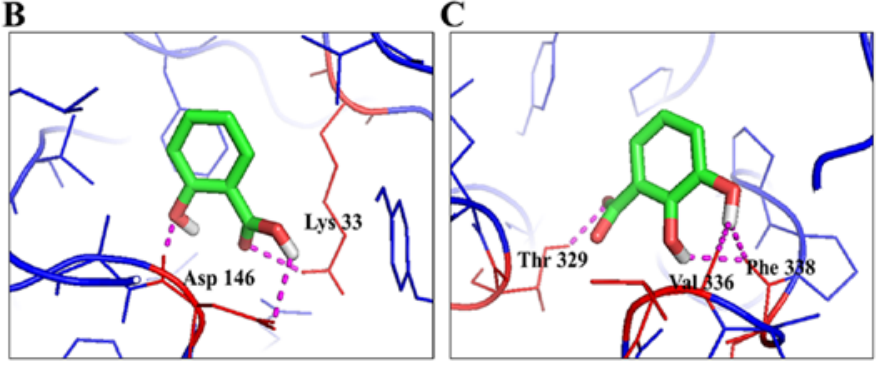

$\mathbf{E}$

CDK1/Cyclin B1_Salicylic acid

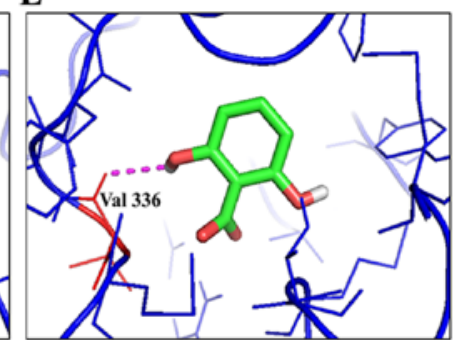

CDK1/Cyclin B1_2,6 DHBA
$\mathbf{F}$

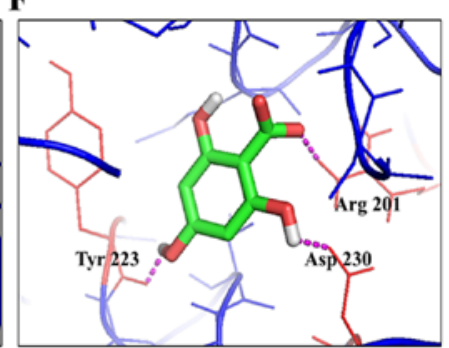

CDK1/Cyclin B1_2,5 DHBA

CDK1/Cyclin B1_2,4,6 THBA

Figure 5. Molecular docking studies showing the potential interactions of aspirin (A), salicylic acid (B), 2,3-DHBA (C), 2,5-DHBA (D), 2,6-DHBA (E) and 2,4,6-THBA (F) with CDK1/cyclin B1 complex.

physical interactions of aspirin, salicylic acid, 2,3-DHBA, 2,6-DHBA and 2,4,6-THBA with CDK1. We hypothesized that if aspirin binds to $\mathrm{CDK} 1$, it should be able to acetylate CDK1 and this could be detected by immunoblotting with anti-acetyl lysine antibody. If this is true, then pre-incubation of CDK1 with salicylic acid, 2,3-DHBA, 2,6-DHBA or 2,4,6-THBA should prevent aspirin-induced CDK1 acetylation. Therefore, first, we tested the ability of aspirin at various concentrations to acetylate recombinant CDK1 (Prospec) in vitro. For this, recombinant CDK1 (300 ng) was incubated with aspirin at various concentrations for $12 \mathrm{~h}$, and then samples were immunoblotted with anti-acetyl lysine antibody. Fig. 6A demonstrates that aspirin dose-dependently acetylated recombinant $\mathrm{CDK} 1$ beginning at $0.25 \mathrm{mM}$ (upper panel). Stripping and reprobing the blot showed similar amounts of CDK1 protein in all lanes (Fig. 6A, lower panel).

The ability of aspirin to acetylate CDK1 as shown in Fig. 6A, supports the results obtained from molecular docking studies which suggested that aspirin potentially binds to CDK1 (Table I). Since salicylic acid also potentially binds to CDK1, we next determined if pre-incubation of CDK1 with salicylic acid would prevent aspirin's ability to acetylate CDK1. For this, recombinant CDK1 was left untreated, or treated with aspirin alone $(1.5 \mathrm{mM})$, or first pre-incubated with different concentrations of salicylic acid for $10 \mathrm{~min}(0.01-0.25 \mathrm{mM})$ and then treated with aspirin $(1.5 \mathrm{mM})$ for $12 \mathrm{~h}$. The samples were then immunoblotted with anti-acetyl lysine antibody. Fig. 6B demonstrates that aspirin caused acetylation of recombinant CDK1; however, this was dose-dependently prevented by preincubation with salicylic acid (upper panel). Reprobing the blot in Fig. 6B showed that all lanes contained equal amounts of CDK1 protein (lower panel).

In similar experiments as mentioned above, we next determined whether pre-incubation of recombinant CDK1 with 2,3-DHBA and 2,6-DHBA would prevent aspirin-mediated acetylation of CDK1. Recombinant CDK1 was pre-incubated with $0.5 \mathrm{mM}$ 2,3-DHBA and 2,6-DHBA for $10 \mathrm{~min}$; then $1.5 \mathrm{mM}$, aspirin was added and the samples were incubated for $12 \mathrm{~h}$ at room temperature. The samples were analyzed by immunoblotting with anti-acetyl lysine antibodies. Fig. 6D (upper panel), demonstrates that pre-incubation of CDK1 with 2,3-DHBA or 2,6-DHBA significantly prevented aspirinmediated acetylation of CDK1. In separate experiments, we also observed that pre-incubation of recombinant CDK1 with 2,4,6-THBA prevented aspirin-mediated acetylation of CDK1 (Fig. 6E, upper panel). These results collectively demonstrate that aspirin, salicylic acid, 2,3-DHBA, 2,6-DHBA and 2,4,6-THBA can all directly bind to CDK1, and support the data obtained from molecular docking studies (Table I).

Aspirin acetylates cellular CDK1. We also performed experiments to determine if exposure of HCT-116 cells to aspirin would acetylate cellular CDK1. Cells were treated with aspirin at various concentrations $(0.25-2.5 \mathrm{mM})$ for $12 \mathrm{~h}$, and lysates prepared and immunoprecipitated with anti-acetyl lysine antibody agarose conjugates and immunoblotted with anti-CDK-1 antibody. Fig. 6F, upper panel, demonstrates that CDK1 was acetylated in aspirin treated samples in a dose-dependent fashion. We also analyzed equal amounts of proteins representing these samples by immunoblotting with anti-CDK1 antibody. Fig. 6F, lower panel, shows that these samples contained similar amounts of CDK1 protein.

Effect of aspirin, salicylic acid, 2,3-DHBA, 2,6-DHBA and 2,4,6-THBA on CDK2, CDK4 and CDK6 enzyme activity. Having demonstrated the ability of 2,3-DHBA, 2,6-DHBA and 2,4,6-THBA to inhibit CDK1 enzyme activity in vitro, we sought to determine if these compounds would also inhibit CDK2, 4 and 6 enzyme activity. Commercially available CDK2 enzymes were pre-incubated with these compounds for $10 \mathrm{~min}$, and then in vitro kinase assays were carried out by providing $\mathrm{H} 1$ histones as substrates. Fig. 7A and B demonstrates that aspirin, salicylic 
A

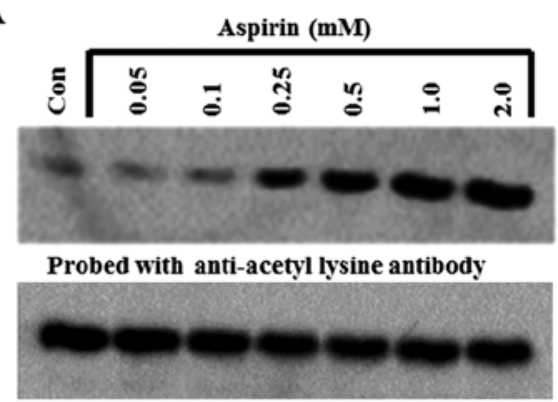

Probed with anti-CDK1 antibody

D
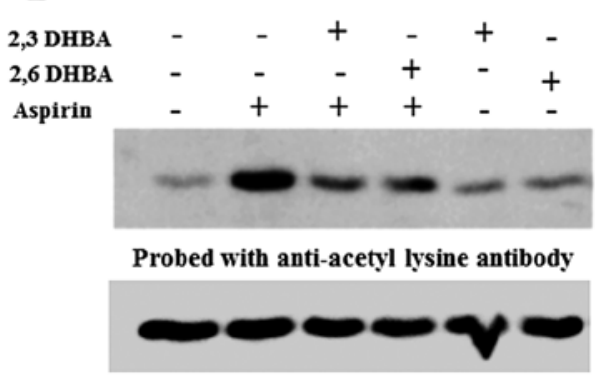

Probed with anti-CDK1 antibody
B

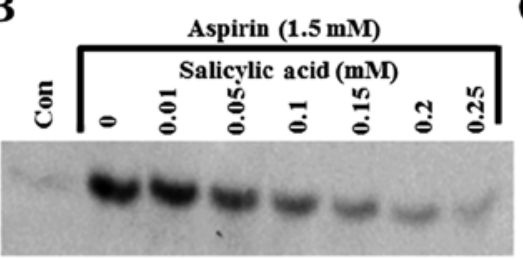

Probed with anti-acetyl lysine antibody

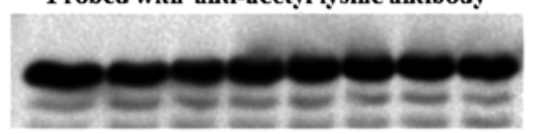

Probed with anti-CDK1 antibody

$\mathbf{E}$

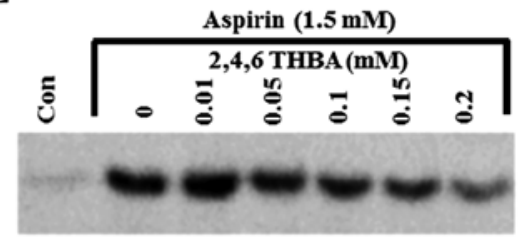

Probed with anti-acetyl lysine antibody

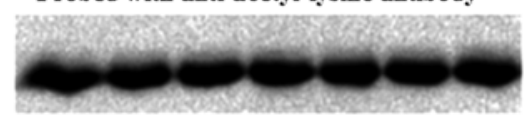

Probed with anti-CDK1 antibody

C

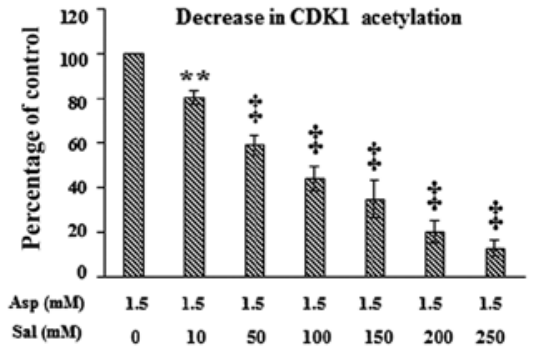

$\mathbf{F}$

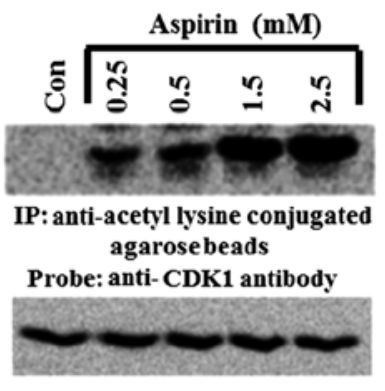

Probed with anti-CDK1 antibody

Figure 6. Aspirin acetylates recombinant CDK1 in vitro and cellular CDK1 in HCT116 cells. (A) Upper panel, dose-dependent effect of aspirin on recombinant CDK1 acetylation. (B) Salicylic acid pre-incubation prevents aspirin-induced acetylation (upper panel). (C) Quantification of blot in (B), the decrease in CDK1 acetylation is expressed as a percentage of the control. (D) Pre-incubation of recombinant CDK1 with 2,3-DHBA and 2,6-DHBA at 0.5 mM prevents aspirin induced acetylation of CDK1 (upper panel). (E) Pre-incubation of recombinant CDK1 with 2,4,6-THBA prevents aspirin induced acetylation of CDK1 (upper panel). (F) Aspirin acetylates cellular CDK1 in HCT-116 cells (upper panel). (F) Lower panel, equal amounts of proteins was immunoblotted with anti-CDK1 antibody. The lower panels in all other blots (A, B, D and E), the upper panel blots were stripped and reprobed with anti-CDK1 antibody. ${ }^{* * *} \mathrm{P}<0.01,{ }^{+} \mathrm{P}<0.001$

acid, 2,3-DHBA and 2,6-DHBA did not inhibit CDK2 activity. However, 2,4,6-THBA showed dose-dependent inhibition of CDK2 enzyme activity (Fig. 7C and D). The $\mathrm{IC}_{50}$ for the inhibition of CDK2 by 2,4,6-THBA was $\sim 300 \mu \mathrm{M}$ (Fig. 7D).

We next performed experiments to determine the effect of aspirin, salicylic acid, 2,3-DHBA, 2,6-DHBA and 2,4,6-DHBA on CDK4 and CDK6 enzyme activity in in vitro kinase assays similar to the experiments performed in Fig. 7A except that retinoblastoma $(\mathrm{Rb})$ protein was provided as substrate for phosphorylation. Fig. 7E and $\mathrm{F}$ demonstrates that aspirin, salicylic acid, 2,3-DHBA and 2,6-DHBA, all failed to inhibit CDK4; however, 2,4,6-DHBA inhibited CDK-4 activity (45\%). Fig. $7 \mathrm{G}$ and $\mathrm{H}$ demonstrates that aspirin and salicylic acid did not affect CDK6 activity; interestingly, 2,3-DHBA, 2,6-DHBA and 2,4,6-THBA significantly inhibited the CDK6 activity by 28,37 and $40 \%$, respectively.

\section{Discussion}

Since the discovery of aspirin in 1897, many of its therapeutic properties and mechanisms of actions have been identified. It is used for a variety of illnesses including inflammation, fever, pain, and for its anti-platelet properties. These actions of aspirin have been attributed mainly to acetylation-mediated inhibition of cyclooxygenases (COX). There are two COX enzymes: COX-1 and COX-2. Aspirin's anti-platelet effect occurs through inhibition of COX-1 $\left(\mathrm{IC}_{50}-1.67 \mu \mathrm{M}\right)$; whereas, its analgesic and anti-inflammatory effects occur primarily through inhibition of COX-2 ( $\left.\mathrm{IC}_{50}-278 \mu \mathrm{M}\right)(27)$. In recent years, evidence has emerged establishing aspirin's ability to decrease cancer incidence, igniting a renewed interest in its research and use. Despite extensive studies, aspirin's mode of action in cancer prevention, as well as how it primarily prevents CRC as compared to other cancers, is not clearly established. Although multiple targets and signaling pathways have been proposed, a unifying mechanism has not been identified till date, suggesting that different mechanisms may be responsible in different cancers or that the actual mechanism is yet to be discovered.

One of the hypotheses proposed for aspirin's anticancer effects is acetylation-mediated inactivation of COX, as upregulation of COX-2 is observed in nearly $80-90 \%$ of CRC; in contrast, COX-1 expression is unaffected (3). The observation that low dose aspirin, used for its cardio-protective effect, is also effective in the prevention of CRC, led to the hypothesis that a common pathway involving COX-1 inhibition in platelets may be central to both effects (28-30). Since low dose aspirin is insufficient to achieve complete inhibition of COX-2, it is argued that aspirin-mediated inhibition of platelet COX-1 plays a role in the prevention of CRC, and that aspirin's effects may occur through sequential steps involving COX-1 and COX-2. It is hypothesized that low dose aspirin by inhibiting COX-1 in platelets prevents their activation and the release of growth factors and lipid mediators, required for COX-2 expression and tumorigenesis in the colonic tissue. While this is a tenable hypothesis, it is yet to be confirmed. 


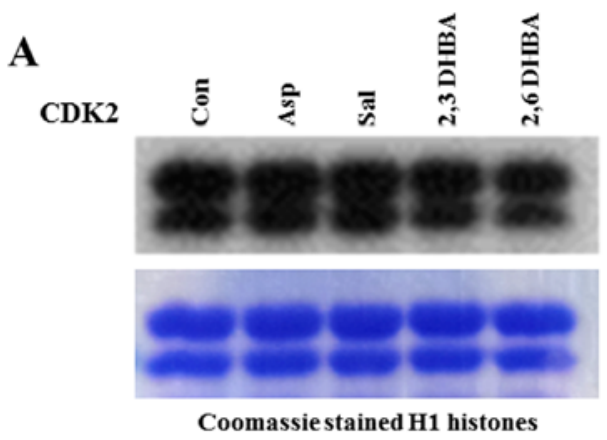

B
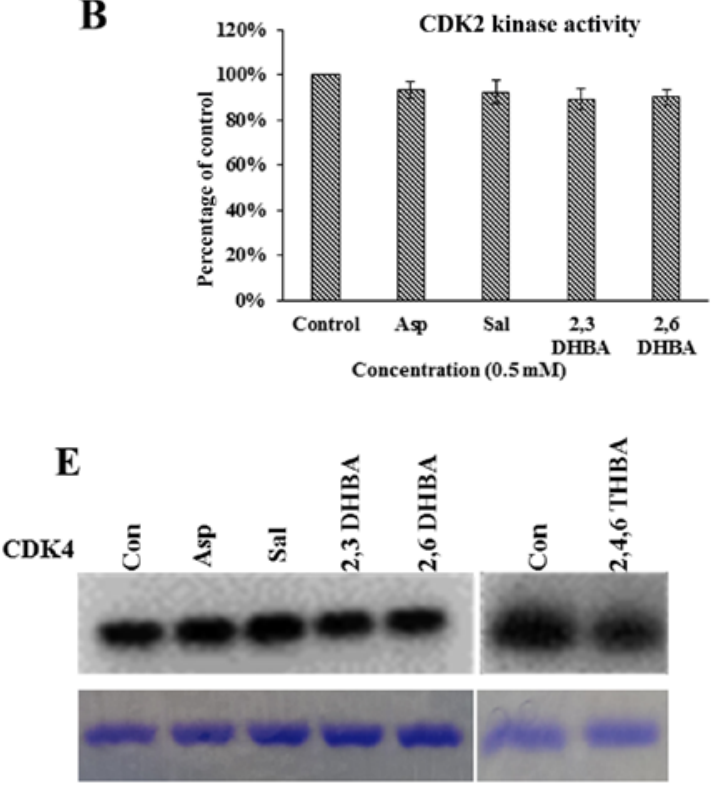

Coomassie stained retinoblastoma

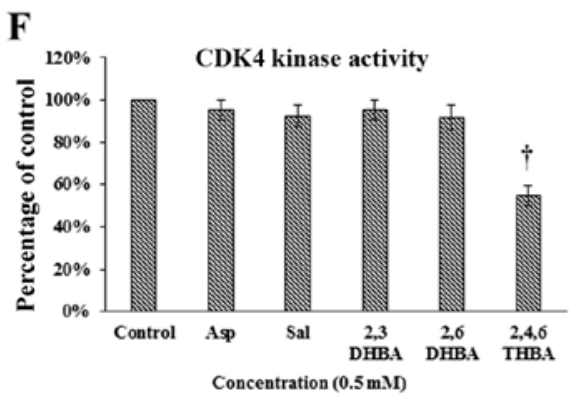

C

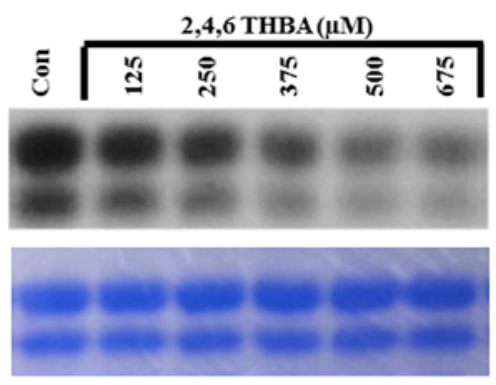

Coomassie stained H1 histones

D

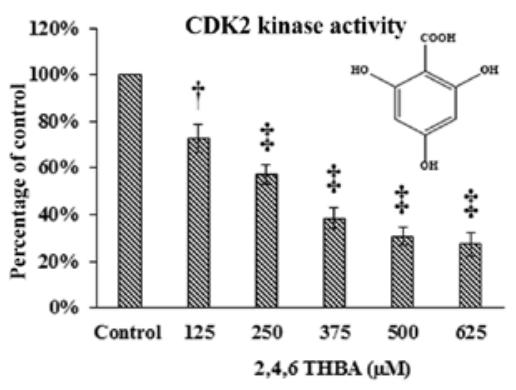

G

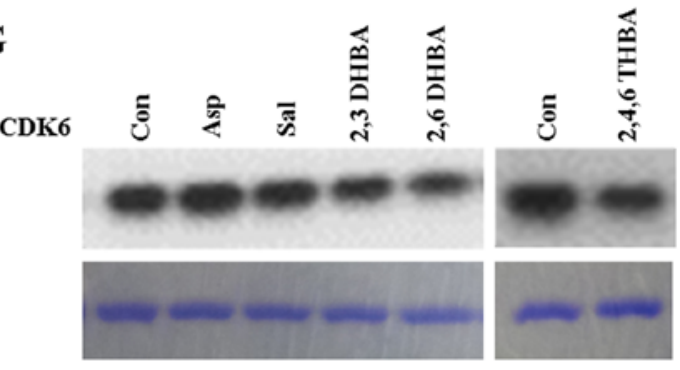

Coomassie stained retinoblastoma

$\mathbf{H}$

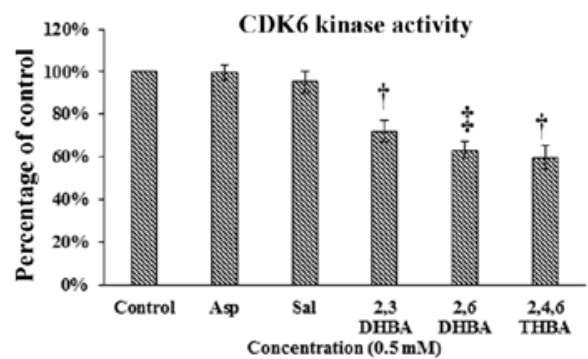

Figure 7. Effect of aspirin, salicylic acid, 2,3-DHBA, 2,6-DHBA and 2,4,6-THBA (at $0.5 \mathrm{mM}$ ) on CDK2, 4 and 6 enzyme activity. (A) Upper panel represents in vitro kinase assays showing the effect of aspirin, salicylic acid, 2,3-DHBA and 2,6-DHBA on CDK2 activity. Lower panel shows coomassie stained $\mathrm{H} 1$ histones. (B) Quantification of the blot in (A). (C) Upper panel represents in vitro kinase assays showing the dose-dependent effect of 2,4,6THBA on CDK2 activity. Lower panel shows coomassie stained H1 histones. (D) Quantification of the blot in (C). (E) Upper panel represents the effect of aspirin, salicylic acid, 2,3-DHBA and 2,6-DHBA and 2,4,6-THBA on CDK4 activity. Lower panel shows coomassie stained retinoblastoma protein. (F) Quantification of the blot in (E). (G) Upper panel represents the effect of aspirin, salicylic acid, 2,3-DHBA and 2,6-DHBA (0.5 mM) and 2,4,6-THBA on CDK6 enzyme activity. Lower panel shows coomassie stained retinoblastoma protein. (H) Quantification of the blot in $(\mathrm{G}) .{ }^{*} \mathrm{P}<0.05,{ }^{* *} \mathrm{P}<0.01,{ }^{\dagger} \mathrm{P}<0.001$, ${ }^{\ddagger} \mathrm{P}<0.001$.

A recent study demonstrated in human intestinal mucosal cells that low-dose aspirin caused acetylation of COX-1 and inhibited PGE2 synthesis leading to decreased levels of S6 kinase, implicating this in the prevention of early colorectal carcinogenesis (31). In addition, salicylic acid, the hydrolyzed product of aspirin, has also been implicated in aspirin's chemopreventive effects. Salicylic acid was shown to bind to a number of cellular proteins (Salicylic Acid Binding Proteins or SABPs) such as IкB kinase (IKK), a component of the NF- $\kappa B$ complex (32), AMP activated protein kinase (33), High Mobility Group Box 1 proteins and GAPDH (34), and CDK2 (19), affecting their levels and/or functional activity.

Although specific protein targets have been identified for both aspirin and salicylic acid, no studies have reported on the cellular targets for salicylic acid metabolites. One of the most important findings of this study is the ability of salicylic acid 
Table II. Effect of aspirin, salicylic acid, 2,3-DHBA, 2,6-DHBA, 2,4,6-THBA and 3,4,5-THBA on CDK-1, 2,4 and 6.

\begin{tabular}{|c|c|c|c|c|c|c|}
\hline & оон & соон & соон & & coon & соон \\
\hline CDKs & Aspirin & Salicylic acid & 2,3-DHBA & 2,6-DHBA & 2,4,6-ТНВА & 3,4,5-ТНВА \\
\hline 1 & - & - & + & + & + & - \\
\hline 2 & - & - & - & - & + & - \\
\hline 4 & - & - & - & - & + & - \\
\hline 6 & - & - & + & + & + & - \\
\hline
\end{tabular}

Effect of aspirin, salicylic acid 2,3-DHBA, 2,6-DHBA, 2,4,6-THBA and 3,4,5-THBA on CDK-1, 2, 4 and 6. Inhibitory effects are shown by plus sign; lack of inhibitory effect is shown by minus sign.

Table III. In vitro $\mathrm{IC}_{50}$ determination for 2,3-DHBA, 2,6-DHBA and 2,4,6-THBA using purified CDK1 enzyme and MTT assay in HCT-116 cells.

\begin{tabular}{lcc}
\hline Compounds & $\begin{array}{c}\text { CDK1 IC } \\
(\mu \mathrm{M})\end{array}$ & $\begin{array}{c}\text { MTT assay HCT-116 } \\
(\mu \mathrm{M}) 72 \mathrm{~h}\end{array}$ \\
\hline 2,3-DHBA & 386.1 & 1778.28 \\
$2,6-\mathrm{DHBA}$ & 365.2 & 1949.84 \\
$2,4,6-\mathrm{THBA}$ & 226.0 & 785.236
\end{tabular}

$\mathrm{IC}_{50}$ values for $\mathrm{CDK} 1$ inhibition in vitro and cytotoxicity assays in HCT-116 cell.

metabolites, 2,3-DHBA and 2,5-DHBA, as well as other derivatives such as 2,4-DHBA, and 2,6-DHBA to inhibit CDK1 enzyme activity in vitro (Fig. 1). Among these, 2,3-DHBA ( IC $_{50}$ $386 \mu \mathrm{M})$ and 2,6-DHBA $\left(\mathrm{IC}_{50} 365 \mu \mathrm{M}\right)$ showed greater degree of inhibition as compared to 2,4-DHBA and 2,5-DHBA. The ability of 2,3-DHBA and 2,5-DHBA to inhibit CDK1 activity is highly significant, because they are known to be generated from salicylic acid metabolism through CYP450-mediated reactions (11). Additionally, in this study, we also screened two THBA derivatives, 3,4,5-THBA and 2,4,6-THBAs, for their ability to inhibit CDK1. We observed that 3,4,5-THBA failed to inhibit; however, 2,4,6-THBA ( $\mathrm{IC}_{50}-226 \mu \mathrm{M}$ ) significantly inhibited CDK1 activity in a dose-dependent fashion. In fact, the degree of inhibition observed with 2,4,6-THBA was greater than that of 2,3-DHBA and 2,6-DHBA (Fig. 1). Not all compounds tested inhibited CDK1 activity in vitro. For example, aspirin, salicylic acid, benzoic acid, 3,4-DHBA 3,5-DHBA, and 5-amino-salicylic acid failed to inhibit CDK1 activity. These results collectively suggest that the DHBAs or THBAs with a common -OH group at the 2nd carbon is likely important for the inhibitory effect on CDK1.

We also performed limited studies to determine the effect of 2,3-DHBA, 2,6-DHBA and 2,4,6-THBA on CDK2, 4 and 6 enzyme activity. We observed that 2,3-DHBA and 2,6-DHBA had either no or marginal effect on CDK2 and 4 (at $500 \mu \mathrm{M}$ ) activity (Figs. 7A and 4E); however, both inhibited CDK6 activity (Fig. 7G). 2,4,6-THBA was highly effective and inhibited all CDKs examined (CDK1, 2, 4 and 6) (Figs. 1G, 7C, $\mathrm{E}$ and $\mathrm{G})$. This suggests that although CDK members share significant homology, the binding pockets for these compounds in CDKs may differ, perhaps accounting for their differential effects. A compilation of the inhibitory effect of 2,3-DHBA, 2,6-DHBA and 2,4,6-THBA on CDK-1, 2, 4 and 6 are shown in Table II. Cytotoxicity assays in HCT-116 cells showed that the $\mathrm{IC}_{50}$ for these compounds differ. For 2,3-DHBA, the $\mathrm{IC}_{50}$ was $\sim 1.8 \mathrm{mM}$; for 2,6-DHBA, it was $1.9 \mathrm{mM}$ and for $2,4,6-$ THBA, it was $0.8 \mathrm{mM}$ (Table III). The $\mathrm{IC}_{50}$ for compound's cytotoxicity in HCT-116 cells is significantly higher than observed for in vitro CDK1 inhibition (e.g., Fig. 1E-H); this may be related to a poor uptake of polyphenolic compounds by cancer cells (35). Our pilot studies using HPLC showed that the cellular uptake of dihydroxy and trihydroxy-benzoic acid are lower as compared to the mono-hydroxy benzoic acid (salicylic acid) (data not shown), possibly reflecting the presence of multiple $\mathrm{OH}$ groups making them more hydrophilic and less absorbable. The poor uptake of HBAs may also be related to the significantly lower expression of monocarboxylate transporters (MCTs, e.g., SLC5A8 and SLC5A12) in metastatic cancer cells (36). Therefore, the effect of these compounds on cellular functions, such as cell cycle regulation, can be better studied after formulation with compounds that can enhance cellular uptake, or in cell lines expressing MCTs. Further work is required to determine, how DHBAs and THBAs affect cell cycle regulation and functions.

Molecular docking studies revealed that aspirin, salicylic acid, 2,3-DHBA, 2,5-DHBA and 2,6-DHBA potentially bind at the same pocket in CDK1; in contrast, 2,4,6-THBA appears to bind to a different site (Fig. 2). Despite the common binding pocket, aspirin and salicylic acid failed to inhibit CDK1; however, 2,3-DHBA, 2,5-DHBA and 2,6-DHBA inhibited CDK1 activity (Fig. 1A-D). Inhibition was also observed with 2,4,6-THBA (Fig. $1 \mathrm{G}$ and $\mathrm{H}$ ). The reason for the inability of aspirin and salicylic acid to inhibit CDK1 activity is not clear at this stage and requires further investigations. All DHBAs potentially showed interaction with Asp146 in CDK1, either through - $\mathrm{COOH}$ or -OH groups. 2,3-DHBA and 2,5-DHBA use- $\mathrm{COOH}$ group; while, 2,6-DHBA uses the -OH group at the 6th carbon to interact with CDK1. Salicylic acid, which 


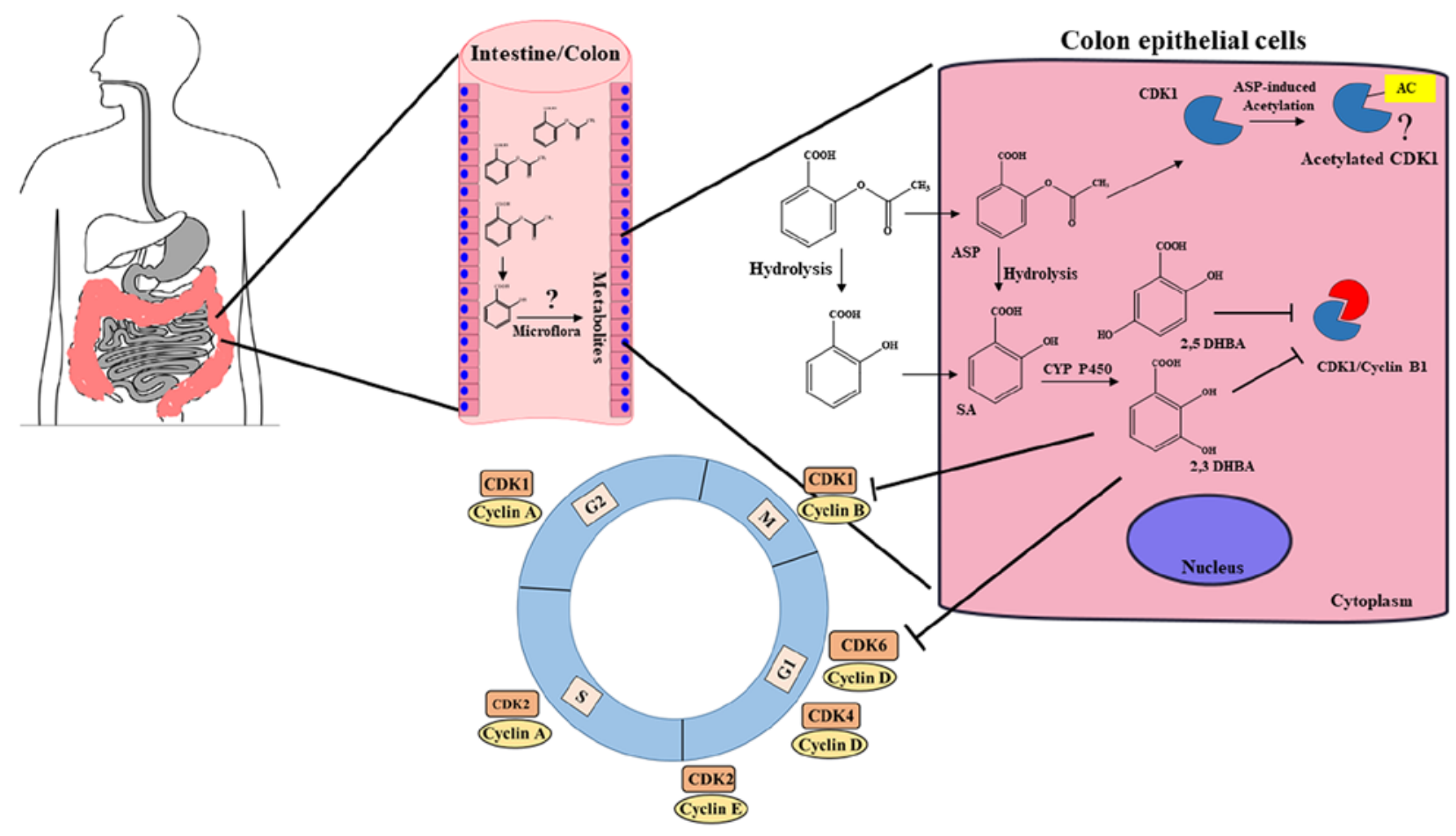

Figure 8. A model depicting how aspirin may preferentially act on colonic tissue to protect against CRC. We suggest that unabsorbed aspirin/salicylic acid in the stomach and upper intestine is passed on to the colon, taken up by the colonic epithelial cells, and metabolized by CYP450s to produce 2,3-DHBA and 2,5-DHBAs. These hydrophilic DHBAs may not easily cross the basolateral membrane of the epithelial cells and within these cells, they may accumulate to pharmacologically relevant concentrations, leading to the inhibition of CDK1 and CDK6, and exert anticancer effects. Colonic epithelial cells may also get exposed to salicylic acid metabolites generated by the gut microflora, and uptake of these HBAs by cells may also cause CDK inhibition. This additional layer of protection against tumor development may be unique to the colonic tissue allowing aspirin as a more effective drug against CRC. (?), Aspirin acetylates CDK1; however, how this modification affects its function is not clear at this stage.

did not show any inhibition of CDK1 appears to interact with Asp146 via the $-\mathrm{COOH}$ group, and with Lys33 via the $-\mathrm{OH}$ group at the 2 nd carbon. It is also interesting to note that 2,4,6-THBA which showed significant inhibition of CDK1 appears to interact with Arg123 via the - $\mathrm{COOH}$ group, and with Arg151 and Gly154 via the -OH group at the 6th carbon (Table I, Fig. 2). These data suggest that the ability of these compounds to inhibit CDK1 is likely determined by the interacting functional groups, as well as their orientation at the binding pocket (Fig. 2), which may affect CDK1 conformation and activity.

In this study, using immunoblotting, we also demonstrated that incubation of recombinant CDK1 (Prospec) monomer with aspirin for $12 \mathrm{~h}$ dose-dependently acetylated CDK1 (Fig. 6A), which was also observed in HCT-116 cells (Fig. 6F). An initial mass spectrometry analysis of aspirin-acetylated CDK1 showed that Lys34 is targeted for acetylation (data not shown). It is not clear at this stage whether this modification affects CDK1 activity; however, the Lys34 is adjacent to the amino acid Lys33 (in the active site). Our in vitro kinase assays using CDK1/ cyclin B1 (NEB) were designed to address how the binding of aspirin affects CDK1 activity by preincubating with aspirin for $10 \mathrm{~min}$, before assaying for $\mathrm{H} 1$ histone phosphorylation. The effect of aspirin-mediated acetylation on CDK1 activity could not be assessed, as the short incubation time (10 min) of CDK1/ cyclin B1 complex with aspirin was insufficient to cause acetylation; longer incubation (12 h) caused degradation (unpublished data). The ability of aspirin to acetylate recombinant CDK1 monomer (Prospec) was taken advantage of to demonstrate the binding of salicylic acid, and its derivatives 2,3-DHBA, 2,6-DHBA and 2,4,6-TBHA to CDK1, in competition experiments. Pre-incubation with all three compounds prevented aspirin-mediated CDK1 acetylation (Fig. 6A-E), which supported the data from molecular docking studies that all compounds potentially bind to CDK1 (Table I). These experiments also show that CDK1 is a salicylic acid binding protein.

It is well established that aspirin is more effective in preventing CRC as compared to other cancers, but a clear explanation for its preferential protective effect in colorectal tissues has not emerged in any reports. Our observation that salicylic acid metabolites 2,3-DHBA and 2,5-DHBA inhibit CDK1 activity provides an important insight into aspirin's chemopreventive actions. This is particularly relevant to the prevention of colon tumorigenesis, as expression of several CYP450 members, including CYP3A4/A5 implicated in aspirin/salicylic acid metabolism in the liver, are also reported to be present in healthy and cancerous colonic tissues (37-40). Although the stomach and upper intestine are the major sites of aspirin absorption, it is likely that some aspirin and its hydrolyzed product, salicylic acid, is passed on to the lower intestine and colon. Moreover, availability of aspirin in the intestine and colon will be much higher after ingestion of enteric coated tablets, as they are designed to resist dissolution in the acidic environment of the stomach. Aspirin and salicylic acid absorbed by the intestinal and colonic epithelial cells may be metabolized by local CYP450s to produce 2,3-DHBA and 2,5-DHBA. Although 2,3-DHBA and 2,5-DHBA are the minor metabolites generated by CYP450 metabolism in the 
liver, the extent to which they are generated in epithelial cells of the GI are unknown, and it is possible that these metabolites may be produced at much higher levels in GI epithelial cells. These intracellularly produced hydroxyl-derivatives of salicylic acid are probably too hydrophilic to cross the basolateral side of the epithelial cell membrane, and within these cells, they may accumulate to pharmacologically relevant concentrations sufficient to inhibit CDKs and act locally to exert anticancer effects. Another source of salicylic acid derivatives for epithelial cell uptake may be generated through GI microflora. The epithelial cells of the intestine/colon are likely to be exposed to higher concentrations of the salicylic acid metabolites and derivatives (HBAs) as opposed to other tissues resulting in the inhibition of CDKs. This additional layer of protection against tumor development may be unique to the colorectal tissue as compared to other tissues such as breast, lung, ovary and skin, allowing aspirin to preferentially act against CRC. A model depicting new insights into aspirin's effect against CRC is shown in Fig. 8. This model envisions that the ability of aspirin to inhibit tumor formation in the intestinal/colonic mucosa is a local effect via locally generated salicylic acid metabolites/ derivatives leading to inhibition of CDKs, and may not require systemic absorption into the blood.

Salicylic acid metabolites 2,3-DHBA and 2,5-DHBA were also reported to be present in the plasma of individuals even when there has been no intake of aspirin, indicating a dietary source (41). It is suggested that diet containing fruits and vegetables may also provide a rich source of HBAs. 2,3-DHBA is present in avocados, batoko plum and in medicinal herbs such as Madagascar rosy periwinkle. 2,5-DHBA is also widely present in fruits including kiwi fruit, aloe vera, mushrooms, apple, bitter melon, blackberries, grapes and pears; it is also present in wine (42). It is important to note that 2,4,6-THBA was demonstrated as one of the in vitro degradation product of catechins by the intestinal bacterium, Acinetobacter calcoaceticus $(43,44)$. In addition, 2,4-DHBA and 2,4,6-THBA were reported to be produced through $\mathrm{pH}$-dependent degradation of anthocyanins (45). The exposure of the colonic epithelial cells to these pharmacologically active CDK inhibitors may provide a link between diet rich in salicylic acid/DHBAs/catechins/ anthocyanins and decreased occurrences of CRC (46-48).

We believe that our observations have opened a new frontier in aspirin research by identifying CDKs as novel cellular targets for salicylic acid metabolites and derivatives. The potential contributions of locally generated HBAs either in the colon or within the colonic epithelial cells, to aspirin's chemopreventive actions against $\mathrm{CRC}$ via $\mathrm{CDK}$ inhibition represent an important area for future research. Against the backdrop of our in vitro observation that salicylic acid metabolites inhibit CDKs, the question is raised whether aspirin through acetylation of COX or other proteins $(7,49)$, or salicylic acid through binding to cellular targets (SABPs) $(19,34)$, or salicylic acid metabolites through inhibition of CDKs, are responsible for the observed chemopreventive effects of aspirin. We suggest that although aspirin's ability to prevent CRC may occur through multiple mechanisms, salicylic acid metabolites formed locally in the colon, or within the intestinal epithelial cells, may contribute significantly to its protective effects. Other interesting questions that need to be addressed include: are there other cellular protein targets for salicylic acid metabolites besides CDKs? Will daily supplements of DHBAs/THBAs capable of inhibiting CDKs provide protection against CRCs? $\mathrm{IC}_{50}$ for the inhibition of CDKs by DHBAs and THBAs are although in micromolar range $(300 \mu \mathrm{M})$, it could be argued that these concentrations are still physiologically relevant. Given the abundance of the occurrences of DHBAs and THBAs in fruits and vegetables (42), it is possible that CDKs have been evolved to be less sensitive to inhibition for these natural compounds avoiding cytotoxicity.

In recent times, attention is increasingly focused on developing CDK inhibitors to arrest cell cycle as a therapeutic intervention to treat cancer. Although several potential CDK inhibitors are undergoing clinical trials, palbociclib and ribociclib are the only FDA approved drugs used in cancer treatment (17). We are hopeful that structural modification to DHBAs and THBAs may potentially lead to the development of novel class of CDK inhibitors for cancer prevention and treatment.

\section{Acknowledgements}

The NIH (5RO3CA133061-02) and Faculty Excellence Funds from the Office of Research, South Dakota State University to G.J.B.; and Women and Giving-2015 Award to R.D. are gratefully acknowledged. We thank Dr Jane Endicott of Newcastle University, UK, for providing the CDK assay protocols, and Mrs. Daniela Paez and members of the Proteomics Core Facility at SD-BRIN (NIH grant no. P20GM103443), USD, for the mass spectrometry analysis. We thank Ms. Mary Carlson for editing the manuscript.

\section{References}

1. Patrignani $\mathrm{P}$ and Patrono $\mathrm{C}$ : Aspirin and Cancer. J Am Coll Cardiol 68: 967-976, 2016.

2. Chan AT, Arber N, Burn J, Chia WK, Elwood P, Hul MA, Logan RF, Rothwell PM, Schrör K and Baron JA: Aspirin in the chemoprevention of colorectal neoplasia: An overview. Cancer Prev Res (Phila) 5: 164-178, 2012.

3. Sostres C, Gargallo CJ and Lanas A: Aspirin, cyclooxygenase inhibition and colorectal cancer. World J Gastrointest Pharmacol Ther 5: 40-49, 2014.

4. Rothwell PM, Wilson M, Elwin C-E, Norrving B, Algra A, Warlow CP and Meade TW: Long-term effect of aspirin on colorectal cancer incidence and mortality: 20-year follow-up of five randomised trials. Lancet 376: 1741-1750, 2010.

5. Bosetti C, Rosato V, Gallus S, Cuzick J and La Vecchia C: Aspirin and cancer risk: A quantitative review to 2011. Ann Oncol 23: 1403-1415, 2012.

6. Rothwell PM, Fowkes FGR, Belch JF, Ogawa H, Warlow CP and Meade TW: Effect of daily aspirin on long-term risk of death due to cancer: Analysis of individual patient data from randomised trials. Lancet 377: 31-41, 2011.

7. Alfonso L, Ai G, Spitale RC and Bhat GJ: Molecular targets of aspirin and cancer prevention. Br J Cancer 111: 61-67, 2014.

8. Pedersen AK and FitzGerald GA: Dose-related kinetics of aspirin. Presystemic acetylation of platelet cyclooxygenase. N Engl J Med 311: 1206-1211, 1984.

9. Bahar FG and Imai T: Aspirin hydrolysis in human and experimental animal plasma and the effect of metal cations on hydrolase activities. Drug Metab Dispos 41: 1450-1456, 2013.

10. Hutt AJ, Caldwell J and Smith RL: The metabolism of aspirin in man: A population study. Xenobiotica 16: 239-249, 1986.

11. Bojić M, Sedgeman CA, Nagy LD and Guengerich FP: Aromatic hydroxylation of salicylic acid and aspirin by human cytochromes P450. Eur J Pharm Sci 73: 49-56, 2015.

12. Grootveld $M$ and Halliwell B: 2,3-Dihydroxybenzoic acid is a product of human aspirin metabolism. Biochem Pharmacol 37: 271-280, 1988. 
13. Malumbres $M$ and Barbacid M: Cell cycle, CDKs and cancer: A changing paradigm. Nat Rev Cancer 9: 153-166, 2009.

14. Peyressatre M, Prével C, Pellerano M and Morris MC: Targeting cyclin-dependent kinases in human cancers: From small molecules to Peptide inhibitors. Cancers (Basel) 7: 179-237, 2015.

15. Brown NR, Korolchuk S, Martin MP, Stanley WA Moukhametzianov R, Noble ME and Endicott JA: CDK1 structures reveal conserved and unique features of the essential cell cycle CDK. Nat Commun 6: 6769, 2015.

16. Hanahan D and Weinberg RA: Hallmarks of cancer: the next generation. Cell 144: 646-674, 2011

17. Hamilton $E$ and Infante JR: Targeting CDK4/6 in patients with cancer. Cancer Treat Rev 45: 129-138, 2016.

18. Roskoski R Jr: Cyclin-dependent protein kinase inhibitors including palbociclib as anticancer drugs. Pharmacol Res 107: 249-275, 2016.

19. Dachineni R, Ai G, Kumar DR, Sadhu SS, Tummala H and Bhat GJ: Cyclin A2 and CDK2 as novel targets of aspirin and salicylic acid: A potential role in cancer prevention. Mol Cancer Res 14: 241-252, 2016

20. Ai G, Dachineni R, Kumar DR, Marimuthu S, Alfonso LF and Bhat GJ: Aspirin acetylates wild type and mutant p53 in colon cancer cells: Identification of aspirin acetylated sites on recombinant p53. Tumour Biol 37: 6007-6016, 2016.

21. Ai G, Dachineni R, Muley P, Tummala H and Bhat GJ: Aspirin and salicylic acid decrease c-Myc expression in cancer cells: A potential role in chemoprevention. Tumour Biol 37: 1727-1738, 2016.

22. Alfonso LF, Srivenugopal KS, Arumugam TV, Abbruscato TJ Weidanz JA and Bhat GJ: Aspirin inhibits camptothecin-induced p21CIP1 levels and potentiates apoptosis in human breast cancer cells. Int J Oncol 34: 597-608, 2009.

23. Van Der Spoel D, Lindahl E, Hess B, Groenhof G, Mark AE and Berendsen HJ: GROMACS: Fast, flexible, and free. J Comput Chem 26: 1701-1718, 2005

24. Senderowicz AM: Flavopiridol: The first cyclin-dependent kinase inhibitor in human clinical trials. Invest New Drugs 17: 313-320, 1999.

25. Sausville EA: Complexities in the development of cyclindependent kinase inhibitor drugs. Trends Mol Med 8 (Suppl): S32-S37, 2002

26. Welburn JP, Tucker JA, Johnson T, Lindert L, Morgan M, Willis A, Noble ME and Endicott JA: How tyrosine 15 phosphorylation inhibits the activity of cyclin-dependent kinase 2-cyclin A. J Biol Chem 282: 3173-3181, 2007.

27. Vane JR, Bakhle YS and Botting RM: Cyclooxygenases 1 and 2. Annu Rev Pharmacol Toxicol 38: 97-120, 1998.

28. Thun MJ, Jacobs EJ and Patrono C: The role of aspirin in cancer prevention. Nat Rev Clin Oncol 9: 259-267, 2012.

29. Dovizio M, Tacconelli S, Sostres C, Ricciotti E and Patrignani P. Mechanistic and pharmacological issues of aspirin as an anticancer agent. Pharmaceuticals (Basel) 5: 1346-1371, 2012.

30. Lichtenberger LM, Fang D, Bick RJ, Poindexter BJ, Phan T, Bergeron AL, Pradhan S, Dial EJ and Vijayan KV: Unlocking aspirin's chemopreventive activity: Role of irreversibly inhibiting platelet cyclooxygenase-1. Cancer Prev Res (Phila) 10: 142-152, 2017.

31. Patrignani P, Sacco A, Sostres C, Bruno A, Dovizio M, Piazuelo E, Di Francesco L, Contursi A, Zucchelli M, Schiavone S, et al: Low-dose aspirin acetylates cyclooxygenase- 1 in human colorectal mucosa: Implications for the chemoprevention of colorectal cancer. Clin Pharmacol Ther 102: 52-61, 2017.
32. Kopp E and Ghosh S: Inhibition of NF-kappa B by sodium salicylate and aspirin. Science 265: 956-959, 1994.

33. Hawley SA, Fullerton MD, Ross FA, Schertzer JD, Chevtzoff C Walker KJ, Peggie MW, Zibrova D, Green KA, Mustard KJ, et al: The ancient drug salicylate directly activates AMP-activated protein kinase. Science 336: 918-922, 2012.

34. Klessig DF, Tian M and Choi HW: Multiple targets of salicylic acid and its derivatives in plants and animals. Front Immunol 7: 206, 2016

35. Manach C, Scalbert A, Morand C, Rémésy C and Jiménez L: Polyphenols: Food sources and bioavailability. Am J Clin Nutr 79: 727-747, 2004

36. Ganapathy V, Thangaraju M, Gopal E, Martin PM, Itagaki S, Miyauchi S and Prasad PD: Sodium-coupled monocarboxylate transporters in normal tissues and in cancer. AAPS J 10: 193-199, 2008.

37. Gervot L, Carrière V, Costet $\mathrm{P}$, Cugnenc $\mathrm{PH}$, Berger $\mathrm{A}$, Beaune $\mathrm{PH}$ and de Waziers I: CYP3A5 is the major cytochrome P450 3A expressed in human colon and colonic cell lines. Environ Toxicol Pharmacol 2: 381-388, 1996.

38. Thelen K and Dressman JB: Cytochrome P450-mediated metabolism in the human gut wall. J Pharm Pharmacol 61: 541-558, 2009.

39. Paine MF, Hart HL, Ludington SS, Haining RL, Rettie AE and Zeldin DC: The human intestinal cytochrome P450 'pie'. Drug Metab Dispos 34: 880-886, 2006.

40. Kumarakulasingham M, Rooney PH, Dundas SR, Telfer C, Melvin WT, Curran S and Murray GI: Cytochrome p450 profile of colorectal cancer: Identification of markers of prognosis. Clin Cancer Res 11: 3758-3765, 2005.

41. Paterson JR, Blacklock C, Campbell G, Wiles D and Lawrence JR The identification of salicylates as normal constituents of serum: A link between diet and health? J Clin Pathol 51: 502-505, 1998

42. Juurlink BH, Azouz HJ, Aldalati AM, AlTinawi BM and Ganguly P: Hydroxybenzoic acid isomers and the cardiovascular system. Nutr J 13: 63, 2014.

43. Arunachalam M, Mohan N, Sugadev R, Chellappan P and Mahadevan A: Degradation of (+)-catechin by Acinetobacter calcoaceticus MTC 127. Biochim Biophys Acta 1621: 261-265, 2003.

44. Gao K, Xu A, Krul C, Venema K, Liu Y, Niu Y, Lu J, Bensoussan L, Seeram NP, Heber D, et al: Of the major phenolic acids formed during human microbial fermentation of tea, citrus, and soy flavonoid supplements, only 3,4-dihydroxyphenylacetic acid has antiproliferative activity. J Nutr 136: 52-57, 2006.

45. Seeram NP, Bourquin LD and Nair MG: Degradation products of cyanidin glycosides from tart cherries and their bioactivities. J Agric Food Chem 49: 4924-4929, 2001.

46. Paterson JR and Lawrence JR: Salicylic acid: A link between aspirin, diet and the prevention of colorectal cancer. QJM 94: 445-448, 2001

47. Kamiloglu S, Capanoglu E, Grootaert C and Van Camp J: Anthocyanin absorption and metabolism by human intestinal Caco-2 cells - A review. Int J Mol Sci 16: 21555-21574, 2015.

48. Kresty LA, Mallery SR and Stoner GD: Black raspberries in cancer clinical trials: Past, present and future. J Berry Res 6: 251-261, 2016.

49. Dovizio M, Bruno A, Tacconelli S and Patrignani P: Mode of action of aspirin as a chemopreventive agent. In: Prospects for Chemoprevention of Colorectal Neoplasia. Springer, pp39-65, 2013. 